\title{
O RACISMO ESTRUTURAL COMO OBSTÁCULO NA PROTEÇÃO DO DIREITO FUNDAMENTAL À VIDA DA MULHER NEGRA BRASILEIRA
}

\section{ARTIGO ORIGINAL}

CASTRO, Bárbara Aparecida Rodrigues de ${ }^{1}$

GONTIJO, Bruna Soares ${ }^{2}$

CASTRO, Bárbara Aparecida Rodrigues de. GONTIJO, Bruna Soares. O Racismo Estrutural como obstáculo na Proteção do Direito Fundamental à vida da mulher negra brasileira. Revista Científica Multidisciplinar Núcleo do Conhecimento. Ano 05, Ed. 10, Vol. 21, pp. 24-43. Outubro de 2020. ISSN: 2448-0959, Link de acesso: https://www.nucleodoconhecimento.com.br/lei/mulher-negra-brasileira

\section{RESUMO}

Os números recentes sobre as condições de vida da mulher negra no Brasil indicam consideráveis contrastes entre a teoria jurídica e a prática dela na sociedade. Diante desse panorama, este artigo busca investigar se o racismo estrutural age como um impeditivo à concretização do direito fundamental à vida da mulher negra brasileira. $\mathrm{O}$ objetivo é buscar respostas e soluções para essa defasagem jurídico-social. O método de pesquisa utilizado neste artigo científico é o dedutivo através da pesquisa bibliográfica. A análise partiu de comparações entre o direito positivado e dados estatísticos para, só no final, para além da "escada ponteana", concluir que não há significativa eficácia social das normas confrontadas, e o principal motivo se deve a sobrevivência do racismo estrutural em nossa sociedade.

Palavras-chave: Mulheres Negras, Direitos Fundamentais, Dignidade da Pessoa Humana, Racismo Estrutural, eficácia social.

\footnotetext{
${ }^{1}$ Graduanda em Direito.

2 Graduanda em Direito.
} 


\title{
1. INTRODUÇÃO
}

\author{
Maria, Maria \\ É um dom, uma certa magia \\ Uma força que nos alerta \\ Uma mulher que merece viver e amar \\ Como outra qualquer do planeta \\ Milton Nascimento[3]
}

\begin{abstract}
"Maria, Maria", composição de Fernando Brant e Milton Nascimento, que ficou conhecida na voz desse último no final da década de 70 , inaugura este trabalho em razão de sua profundidade e abrangente rede de interpretações que transcende a textualidade, bem como a referenciamos em razão da história a que esta faz alusão ao que remonta os fatos, a letra retrata uma mãe solo, pobre, que morava na beira dos trilhos de trem, cuidava de três filhos e passava muita dificuldade. Por óbvio o objetivo aqui não é a interpretação linguística da música, história musical, harmonia musical ou um possível reforço ao imaginário social estigmatizado. Ao contrário; o presente é um lembrete à dignidade da pessoa humana, mais especificamente a dignidade da mulher, pois toda mulher "merece viver e amar como outra qualquer no planeta".
\end{abstract}

Alguns leitores questionarão a necessidade de se "dissociar" um grupo de mulheres e as alçar a análise em recorte, especialmente em um país onde há uma "democracia racial", uma miscigenação e um convívio amigável entre as "raças".

"Cá entre a gente" - em "pretuguês"[4], de Lélia Gonzalez[5] -, continuar a enxergar e tratar todas as mulheres de forma universalizada é temeroso. Pode parecer contraditório ao que foi dito acima, principalmente no âmbito jurídico, não obstante, falamos da perspectiva material da igualdade. Desde Aristóteles é sabido que os diferentes devem ser tratados de forma diferenciada na medida de sua desigualdade. Nas ciências jurídicas e filosóficas tal ideal não é novo, sendo, por isso, rechaçado 
atualmente, pelos motivos acima elencados, integrantes de um imaginário social onde não há injustiças a serem combatidas.

Felizmente, ao nomear estas diferenças, questionamos a "Democracia de todos" e acabamos por visibilizar diferentes realidades, visto que são diferentes os tipos de opressões que podem se interseccionar em uma mesma pessoa e num mesmo grupo de mulheres.

As desigualdades sociais estão presentes na sociedade para quem quiser ver e quando direcionamos nosso olhar ao público negro feminino não é diferente. $A$ violência contra as mulheres negras aumenta desenfreadamente; o modelo penal cada vez mais punitivo não tem surtido o efeito esperado de diminuir a incidência criminosa contra estas; as oportunidades de trabalho se mantém atreladas a ocupação de doméstica; a representatividade no meio eleitoral se mostra insignificante em números precisos; e as condições básicas de saúde, educação e proteção à maternidade não chegam nem perto de propiciar uma vida digna.

Como mostraremos, os números recentes indicam uma defasagem jurídica na proteção e nas condições de vida dessas mulheres. Dessa forma há um contraste entre a teoria jurídica e a prática dela na sociedade. Assim, o que buscamos nesse trabalho é saber o porquê dessas diferenças existirem ou pelo menos tentar buscar um.

À vista disso, o presente artigo elenca o racismo estrutural como determinante na obstrução da efetividade do direito fundamental à vida destas mulheres no Brasil. Isto é, pretende-se demonstrar que o racismo estrutural é um obstáculo a concretização do direito fundamental à vida das mulheres negras.

O método de pesquisa utilizado neste artigo científico é o dedutivo através da pesquisa bibliográfica, pautado em abordagens teóricas sobre o feminismo negro, a antropologia e a sociologia, conferindo ao Direito, através do diálogo dessas fontes, o poder de transformador social.

Enfim, que este lugar de fala[6] nos permita explanar a "dororidade"[7]. 


\section{DIGNIDADE DA PESSOA HUMANA}

Inicialmente, é importante trazer à baila que a dignidade da pessoa humana, os direitos do homem, bem como os direitos fundamentais são três nomenclaturas comumente utilizados como sinônimos, mas que em muito se diferem.

Segundo Ingo Wolfang Sarlet (2019), os direitos do homem estariam ligados aos direitos naturais não positivados ou ainda não positivados, os direitos humanos seriam aqueles positivados na esfera do direito internacional e os direitos fundamentais seriam aqueles reconhecidos, outorgados e protegidos pelo direito constitucional interno de cada Estado.

Isto posto, os direitos do homem estariam ligados as ideias filosóficas jusnaturalistas, onde o direito natural é universal, inerente ao homem e imutável, ao passo que os direitos humanos seriam aqueles encontrados na Declaração Universal dos Direitos Humanos, ou seja, um direito internacional e supranacional; e, por fim, os direitos fundamentais seriam aqueles positivados ou reconhecidos na Carta Maior

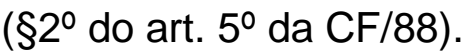

De tal sorte o tema deste tópico é a Dignidade da Pessoa Humana, dignidade esta inerente a toda e qualquer pessoa, afinal "todos os seres humanos nascem livres e iguais em dignidade e direitos. São dotados de razão e consciência", letra do artigo I da Declaração Universal dos Direitos Humanos (DUDH), premissa reconhecida como fundamento do nosso Estado Democrático de Direito (art. 1ํ, inc. III, da CF/88).

Expõe Sarlet (2019, p. 70) o seguinte conceito sobre o que seria a Dignidade da Pessoa Humana:

[...] a qualidade intrínseca e distintiva reconhecida em cada ser humano que o faz merecedor do mesmo respeito e consideração por parte do Estado e da comunidade, implicando, nesse sentido, um complexo de direitos e deveres fundamentais que assegurem a pessoa tanto contra todo e qualquer ato de cunho degradante e desumano, como venham a lhe garantir as condições existenciais mínimas para uma vida saudável além de propiciar e promover sua participação ativa e corresponsável nos destinos da própria existência e da vida em 
comunhão com os demais seres humanos, mediante o devido respeito aos demais seres que integram a rede da vida.

Sarlet (2019) também nos traz a ideia de que esta Dignidade deve ser um limite e uma tarefa não só ao Estado, mas a toda comunidade, condição esta dúplice, eis que há uma conexão entre a dimensão defensiva e prestacional da dignidade.

Nesse sentido, existe um limite a ser respeitado, fixo e imutável; há uma tarefa (prestação) direcionada ao Estado, para que este preserve a dignidade da pessoa humana e crie condições para que tal direito seja promovido e usufruído, sendo tal promoção umbilicalmente dependente da ordem social comunitária.

\section{DIREITOS FUNDAMENTAIS}

O gênero normas contém em seu bojo a espécie "normas constitucionais", mantendo no subtipo as características vitais destas, dentre elas a imperatividade. Para Barroso (2018) a imperatividade tem sua tradução no caráter obrigatório da norma e, por conseguinte, no dever jurídico imposto a seus destinatários, de a ela se submeterem. E caso seja inobservada, será utilizada a coação estatal.

Direitos fundamentais são direitos essenciais garantidos a todos os brasileiros e estrangeiros residentes ou de passagem pelo país (art. 5ํㅡ, caput, da CF/88). São normas positivadas através do tempo, pertencentes por natureza ao ser humano.

Na obra "Justiça, cidadania e democracia", no capítulo sobre igualdade, Airton Florentino de Barros (2009) preleciona que somente o Estado pode exigir o cumprimento das obrigações e garantir o exercício dos direitos fundamentais ao mesmo tempo, eis que a própria existência do Estado só se justifica quando este assegura o exercício de tais direitos, por seu estatuto principal e sua administração.

Os direitos fundamentais são divididos em dimensões. Dimensões estas que se complementam, ao contrário do que dava a entender sua antiga nomenclatura, gerações. Sua classificação está diretamente ligada ao lema da Revolução Francesa 
- liberdade, igualdade e fraternidade. Barroso (2018, p. 115) os correlaciona da seguinte maneira:

Na primeira geração encontram-se os direitos individuais, que traçam a esfera de proteção das pessoas contra o poder do Estado, e os direitos políticos, que expressam os direitos da nacionalidade e os de participação política, que se sintetizam no direito de votar e ser votado. Na segunda geração estão os direitos sociais, econômicos e culturais, referidos normalmente como direitos sociais, que incluem os direitos trabalhistas e os direitos a determinadas prestações positivas do Estado, em áreas como educação, saúde, seguridade social e outras. Na terceira geração estão os direitos coletivos e difusos, que abrigam o direito ao meio ambiente ecologicamente equilibrado e os direitos do consumidor. Já se fala em uma quarta geração, que compreenderia o direito à democracia e ao desenvolvimento.

Conforme se extrai 0 art. $5^{\circ}, \S 1^{\circ}$ da Carta Magna, os direitos fundamentais têm aplicação imediata. Na lição de Miguel Reale (2012, p. 104), as normas fundamentais de aplicação imediata "são aquelas normas da Constituição que, no momento em que esta entra em vigor, estão aptas a produzir todos os seus efeitos, independentemente de norma integrativa infraconstitucional".

Todavia, existem aquelas normas que, apesar de sua aplicabilidade imediata, possuem a chamada eficácia contida, que de acordo com Sarlet (2019), são aquelas que possuem restringidos os seus efeitos, sendo assim, não resta afastada a possibilidade de que sejam estabelecidas restrições a direitos fundamentais que não foram colocados pelo legislador constituinte sob uma expressa reserva legal, eis que inexiste, ao menos a princípio, direito fundamental totalmente imune a toda e qualquer limitação.

Como exemplo de norma contida, podemos citar aquela prevista no art. $5^{\circ}$, Inc. XIII, da Constituição, a qual dispõe que, apesar de ser livre o exercício de qualquer trabalho, ofício ou profissão, para que tal ocorra, deve-se atender as qualificações profissionais que a lei estabelecer.

Por outro lado, os direitos sociais, tidos como de segunda dimensão, têm sua eficácia diferida, mediata, tendo em vista que sua previsão é programática, tratando-se de 
diretrizes que necessitam de ações positivas por parte do Estado para serem concretizadas. Na lição de Reale (2012) as normas de eficácia limitada, declaratórias de princípios programáticos, trazem programas a serem implementados pelo Estado, aspirando a realização de fins sociais.

Algumas matérias tratadas no corpo constitucional apresentam-se como imutáveis

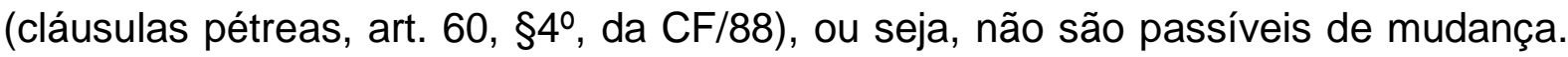
São elas: a forma federativa de Estado; o voto direto, secreto, universal e periódico; a separação dos Poderes; os direitos e garantias individuais[8]. (grifo nosso)

Por se tratar de um tema não taxativo, que abarca direitos fundamentais fora do catálogo e direitos fundamentais materialmente constitucionais, trataremos com maior ênfase do direito fundamental de primeira dimensão, do Título I, caput, do art. $5^{\circ}$ da CF/88: direito à vida, bem como aqueles que, através do conceito de mínimo existencial', são necessários para uma vida digna.

\subsection{DIREITO À VIDA}

Na constituição federal está insculpido no caput do art. 50: "Todos são iguais perante a lei, sem distinção de qualquer natureza, garantindo-se aos brasileiros e aos estrangeiros residentes no País a inviolabilidade do direito à vida" [...]. (Grifo nosso).

Já no início de seus artigos, podemos visualizar traços fortes e presentes de tal proteção, que se vê ancorada nos objetivos fundamentais da República, a qual "promove o bem de todos, sem preconceitos de origem, raça, sexo, cor, idade e quaisquer outras formas de discriminação" (art. $3^{\circ}$, Inc. IV) e, estabelece em suas relações internacionais "a prevalência dos direitos humanos" (art. $4^{\circ}$, Inc. II).

A Carta Maga, ao proteger o direito à vida, não nos deu uma definição clara do que seria "vida", cabendo a doutrina, assim como a ciência, nos explicar o que seria vida, o intervalo de tempo desta, quando se inicia e quando incide a proteção estatal.

Vida significa "período de tempo compreendido entre o nascimento e a morte de um ser vivo; existência"[9]. 
Segundo ensinamento de José Afonso da Silva (2005), o direito à vida constitui fonte primária de todos os outros bens jurídicos. Logo, não adiantaria que a Constituição promovesse a proteção de outros direitos fundamentais, tais como o direito à liberdade, à igualdade, à integridade física e moral, se não inserisse neles a vida humana.

Ou seja, o direito em comento compreende não só o ato de nascer, mas uma proteção jurídica que perdura até a morte natural e atua contra qualquer meio que vá na contramão disso, ainda que a infringência não decorra de ações humanas diretas.

Sobre a abrangência, Vicente Paulo e Marcelo Alexandrino (2020) dispõe que o direito fundamental à vida possui aspecto biológico, o qual traduz o direito à integridade física e psíquica, e sob aspecto amplo, traduz o direito a condições espirituais e materiais necessárias a uma existência digna à natureza humana.

Para Paulo Gustavo Gonet Branco (2017), o direito à vida é a premissa dos direitos proclamados pelo constituinte; pois não faria sentido apresentar qualquer outro se antes não fosse protegido o princípio manifesto de estar vivo para dele se usufruir.

\subsection{MÍNIMO EXISTENCIAL}

Os direitos fundamentais em discussão são muitos, sendo eles capazes de proporcionar uma existência digna ao ser humano, inferência esta de um Estado Social Democrático. Por isso, a existência digna nos remete a ideia de um mínimo existencial que é longa manus do direito à vida. Eis que sem ele não seria possível viver.

O mínimo existencial seria o conjunto de prestações/condições básicas de vida que exige por parte do Estado uma atuação positiva, fazendo com que este busque efetivar, na verdade, os direitos fundamentais sociais, aqueles encontrados no art. $6^{\circ}$ da $\mathrm{CF} / 88$, tais como moradia, saúde, educação, alimentação, trabalho, proteção à maternidade etc. (art. $6^{\circ}$, caput, $\mathrm{CF} / 88$ ). 
Conforme ensina Fernandes (2016), tais garantias de condições de vida básicas, para alguns doutrinadores, seriam diretamente ligadas à autonomia individual e à saúde, o que também faz referência, de modo reflexo, à alimentação, moradia, educação, dentre outros. Para outros, indicariam um conteúdo relativo ao mínimo existencial, que não poderia, portanto, ser definido a princípio sem ser levada em conta uma situação específica, concreta e contextualizada.

Por fim, Barroso (2018) nos diz que a partir do núcleo vital do princípio da dignidade da pessoa humana é que emanam todos os direitos materialmente fundamentais, que por tamanha importância devem receber proteção máxima do Estado, independentemente de sua posição formal, da dimensão a que pertencem e do tipo de prestação a que dão ensejo.

\subsection{A ATUAÇÃO DO ESTADO NA PROTEÇÃO DO DIREITO À VIDA MULHER E DA PESSOA NEGRA}

A ideia da mulher como sujeito de direitos no ordenamento jurídico dos Estados Modernos é uma questão recente. Somente a partir do séc. XX a luta feminista conseguiu espaço nas agendas públicas para se fazer reconhecer seus direitos.

No Brasil, os primeiros avanços na busca pela proteção dos direitos das mulheres ocorreram na década de 1980, com a criação das Delegacias das Mulheres, as quais, todavia, não existem, de acordo com o portal Agência Brasil[10], em 91,7\% das cidades brasileiras, sendo que em $90,3 \%$ das cidades não há qualquer tipo de serviço especializado no atendimento à vítima de violência sexual.

Em 1979 a Convenção sobre a Eliminação de Todas as Formas de Discriminação contra as Mulheres foi assinada na ONU e em 1984 ratificada pelo Brasil. A Convenção objetivava uma dupla obrigação: de eliminar a discriminação e de obter a igualdade. Em tal documento é prevista a possibilidade de ações afirmativas como meio de se impulsionar e acelerar a obtenção de igualdade. 
A fim de se assegurar o direito à vida, bem como o da integridade física e psíquica das mulheres, somente em agosto de 2006 foi sancionada a Lei Maria da Penha ( $\mathrm{n}^{\circ}$ 11.340), a qual criou mecanismos para coibir a violência doméstica e familiar contra a mulher, tendo sido recentemente alterada pela Lei 13.827/2019, tratando especificamente da articulação de gênero/raça em algum de seus artigos. Dentre eles podemos citar 0 art. $2^{\circ}$, cuja redação é o seguinte:

Toda mulher, independente de classe, raça, etnia, orientação sexual, renda, cultura, nível educacional, idade e religião, goza dos direitos fundamentais inerentes à pessoa humana, sendo-lhe asseguradas as oportunidades e facilidades para viver sem violência, preservar sua saúde física e mental e seu aperfeiçoamento moral, intelectual e social (Grifo nosso).

Foi acrescido também pela Lei 13.104 de 09 de março de 2015, o Inc. VI no art. 121, $\S 2^{\circ}$, do Código Penal, que trata do feminicídio (homicídio cometido contra a mulher por razões da condição de sexo feminino) como qualificadora do crime de homicídio.

Além disso, existem projetos de lei voltados à defesa dos direitos das mulheres, dentre os quais podemos citar o PL 10986/2018, o qual visa tornar obrigatória a manutenção de ao menos 01 (um) exemplar da Lei Maria da Penha em escolas, bibliotecas públicas, unidades de saúde, hospitais públicos e delegacias de polícia.

Ademais, cumpre ressaltar a existência da cota de $30 \%$ para gênero nas eleições proporcionais, comando instituído pela Lei $12.034 / 09$, bem como a instituição do Estatuto da Igualdade Racial (Lei 12.288/2010), estatuto que inspirou a criação da Lei de Cotas no Serviço Público Federal (Lei 12.990/2014) e Lei de Cotas no Ensino Superior (Lei 12.711/2012).

\section{A CONDIÇÃO DE VIDA DAS MULHERES NEGRAS NO BRASIL}

A última pesquisa realizada pelo Instituto de Pesquisa Econômica Aplicada (Ipea) e pelo Fórum Brasileiro de Segurança Pública (FBSP), seguindo dados do Ministério da Saúde compilados no Atlas da Violência, lançado em 2019, traça um cenário de aumento na taxa de nacional de homicídios femininos entre os anos de 2007 e 2017 , 
especialmente entre mulheres negras. Elas viram seu número de homicídios crescer mais de $60,5 \%$ em uma década, em comparação com um crescimento de 1,7\% nos assassinatos de mulheres não negras.

Além disso, na pesquisa elaborada pelo Fórum Brasileiro de Segurança Pública para o Anuário de Segurança Pública, as mulheres negras contabilizam $66 \%$ dos casos de homicídios femininos no país (feminicídios).

Quando o assunto é trabalho, a mulher negra foi relegada a ocupações informais, com ênfase no serviço doméstico. Em apontamento de dados recentes do Ipea, estudos colhidos pelo Instituto Ethos, que traçam o perfil do trabalhado doméstico no país, destaca-se que as desigualdades são maiores para as mulheres negras, sendo mais de 6 (seis) milhões de brasileiros trabalhando em serviços domésticos (motoristas, diaristas, mensalistas, babás, cuidadoras, jardineiros etc.) e desse total $92 \%$ são mulheres (5,7 milhões), a grande maioria negra (68\%), com baixa escolaridade e provenientes de famílias pobres.

É interessante notar que, usando os dados coletados acima, percebemos que se trata de 3,9 milhões de mulheres negras exercendo serviço doméstico; ou seja, temos quase um quinto da população feminina negra composta de domésticas.

Prosseguindo nesse diapasão trabalhista, das "500 Empresas mais admiradas", em suas lideranças existem somente $4,7 \%$ de negros e, num recorte de gênero, apenas $0,4 \%$ dos cargos executivos são ocupados por mulheres negras.

Um levantamento realizado pelo jornal Correio Braziliense[11] apontou que nas eleições de 201813 mulheres negras foram eleitas para o Congresso Nacional (sendo 12 deputadas federais e uma senadora, das quais três são autodeclaradas pretas e dez autodeclaradas pardas). O resultado equivale a apenas $2 \%$ do total de cadeiras da Câmara dos Deputados e do Senado Federal. Em relação aos cargos de deputados estaduais e vereadores, mulheres negras representam, respectivamente, $4,8 \%$ e $5 \%$.

Se analisarmos os salários, segundo a pesquisa "Desigualdades Sociais por Cor ou Raça" publicada pelo IBGE, a mulher branca ganha $70 \%$ a mais que a mulher negra, 
sendo que a média salarial das brancas é de $R \$ 2.379$ e das negras é de $R \$ 1.394$. $E$ se fizermos um recorte de gênero, as mulheres negras não ganham só menos que mulheres brancas, mas também menos que os homens negros, que arrecadam $R \$$ 1.762, e homens brancos com $\mathrm{R} \$ 3.138$.

Ainda, segundo o IBGE, cerca de $40 \%$ das mulheres negras não possuem acesso à rede tubular de esgoto e água. Em comparativo, 26,7\% das mulheres brancas enfrentam o mesmo infortúnio. Nesse percalço, quanto à água encanada são 13,9\% contra $9,4 \%$ e no que se refere à ausência de coleta de lixo são 8,8\% contra 3,7\%[12].

Existem estigmas que embasam os dados da mulher negra na saúde pelo mito de que "são mais fortes", "têm os quadris mais largos", "são parideiras natas", de acordo com a pesquisa "Nascer no Brasil" da Fio Cruz (Fundação Oswaldo Cruz), que embasou o artigo "A cor da dor: iniquidades raciais na atenção pré-natal e ao parto no Brasil", a mulher negra, apesar de sofrer menos epistomias - corte realizado na região do períneo, apto a dar passagem ao bebê em partos normais - que as mulheres brancas, em comparação as mesmas, tem a chance $50 \%$ maior de não receber anestesia local para a realização do procedimento.

De acordo com a pesquisa acima citada, a violência obstétrica é um acontecimento que atinge uma em cada quatro mulheres no Brasil. São dados do Ministério da Saúde e, desses alvos, 65,9\% são mulheres negras. Na mesma pesquisa, 27\% das negras tiveram acompanhamento durante a gestação e 62,8\% das mortes maternas são de mulheres negras.

Ademais, na Pesquisa Nacional por Amostra de Domicílios (PNAD) 2016, de acordo com o relatório as mulheres brancas que conseguiram completar o ensino superior representam o percentual de $23,5 \%$, quase o dobro do de pretas e pardas $(10,4 \%)$.

\section{EFICÁCIA SOCIAL DA NORMA}

Prosseguindo, aprendemos nas lições de Pontes de Miranda (2018) (Barroso apud Pontes de Miranda) sobre a "escada ponteana", na qual devemos nos 
atentar a três planos diferentes para alcançar os efeitos normativos completos da norma: o de existência, o de validade e o de eficácia. Contudo, para o doutrinador Luís Roberto Barroso, foi negligenciado um quarto plano, o da efetividade ou eficácia social da norma.

Nas palavras de Barroso (2018, p. 42) a efetividade social ou eficácia social da norma:

[...] designa a atuação prática da norma, fazendo prevalecer, no mundo dos fatos, os interesses por ela tutelados. Ela expressa a aproximação, tão íntima quanto possível, entre o dever ser normativo e o ser da realidade social. Ao ângulo subjetivo, efetiva é a norma constitucional que enseja a concretização do direito que nela se prevê, propiciando o desfrute real do bem jurídico assegurado.

Na esteira do que Barroso (2018) ensina, busca-se não só a eficácia jurídica como possibilidade de aplicação da norma, mas sua eficácia social, meios para alcançar sua aplicação e efetividade.

Ocorre que, como já dito anteriormente, uma vez que as situações de vulnerabilidade da mulher negra não são levadas em conta pelo ordenamento jurídico brasileiro, tal conexão entre as normas e os fatos sociais não ocorre, fazendo com que a norma não atinja sua eficácia social. Isso ocorre, como tentaremos explicar a seguir, devido a não observância do fenômeno da interseccionalidade junto ao racismo estrutural.

\section{INTERSECCIONALIDADE}

À vista do que até aqui foi exposto, observamos que as mulheres negras, em sua maioria, sofrem por três opressões simultâneas: a de gênero (sexismo), a de classe (pobreza) e a de raça (racismo).

Esse encontro de opressões vivenciadas pela mesma pessoa foi cunhado pela intelectual afro-estadunidense Kimberle Crenshaw como interseccionalidade, termo que sugere a sobreposições de opressões. Nas palavras da estudiosa do tema, Karla Akotirene (2018, p. 19): 
a interseccionalidade visa dar instrumentalidade teórico-metodológica à inesperabilidade estrutural do racismo, capitalismo e cisheteropatriarcado - produtores de avenidas identitárias em que mulheres negras são repetidas vezes atingidas pelo cruzamento e sobreposição de gênero, raça e classe, modernos aparatos.

Nos dizeres da estudiosa Akotirene (2018) a interseccionalidade evita aforismos somatórios, estruturados ou confrontados. Em vez disso, identifica as identidades sociais, se prestando a analisar quais condições da estrutura social transpassam os corpos.

Kimberlé Crenshaw (2012) aduz que é necessária a adoção de uma abordagem de baixo para cima na coleta de informações, ao invés de se pensar de cima para baixo em termos de categorias, de raça e gênero. É necessário ir até as pessoas para enxergar como tais fatores se combinam e determinam suas condições de vida, pois só assim não se deixará de perceber o que pode acontecer com as mulheres negras.

Ainda, para a intelectual a intersecionalidade oferece um caminho para fazermos com que todas as nossas políticas públicas e práticas sejam, efetivamente, inclusivas e alcançadas.

Nota-se, a interseccionalidade investiga a matriz, indo na origem das opressões responsáveis pelas produções de diferenças sociais. Uma vez identificados os componentes integrantes da identidade social que moldam essas diferenças, entenderemos como essas opressões combinadas atuam na vida da mulher negra.

\section{RACISMO ESTRUTURAL}

Pontua Silvio Almeida (2019) que as mulheres negras são consideradas pouco capazes devido à existência de todo um sistema político, econômico e jurídico que faz transparecer essa condição de subalternidade, mantendo-as com baixos salários, expostas a todo tipo de violência e fora dos espaços de decisão.

Na mais esplêndida explicação sobre o tema, o brilhante autor da obra "Racismo Estrutural", situa: o lugar da mulher negra na base da pirâmide social; a quantidade 
de tributos que recaem sobre estas consumidoras; a dificuldade da mulher negra de sair de seu lugar "posto" de doméstica, dentre outros fenômenos aviltantes aos direitos fundamentais destas, como consequências de um racismo de bases estruturais.

Para o autor (2019, p. 65) "o racismo constitui todo um complexo imaginário social que a todo momento é reforçado pelos meios de comunicação, pela indústria cultural e pelo sistema educacional". Expõe que a existência do racismo exige que a desigualdade social seja naturalmente atribuída a algumas identidades sociais, enquanto que para outros grupos raciais atua como atribuição natural privilégios.

Para entender melhor sobre o assunto, o autor diferenciou termos tidos como similares nos dizeres populares, mas que em muito se diferenciam. Vejamos:

O Preconceito racial (relação com a subjetividade): de ordem psicológica, é um ato pré-concebido estruturado em crenças pré-estabelecidas acerca de um indivíduo que pertença a determinado grupo social. Pode ou não resultar em práticas discriminatórias.

A Discriminação (relação com grupos): está ligada ao poder e é utilizada como mecanismo de segregação ou qualquer outro tratamento diferenciado direcionado a grupos nacionalmente identificados. Divide-se em discriminação direta e indireta. A primeira se dá através da ação livre e voluntária do indivíduo em praticar e propagar atos discriminatórios, ao passo que a segunda ocorre por meio da omissão, ao se presenciar um fato discriminatório e não intervir, ignorando-o (discriminação de fato). Ainda, existe a discriminação positiva, o que na seara jurídica é conhecida como do princípio da isonomia, apta a corrigir desvantagens causadas pela discriminação negativa (a responsável por prejuízos e desvantagens).

No que tange ao Racismo: este estaria dividido em três concepções: individualista, institucional e estrutural.

Individualista (explícito): o racismo nessa concepção seria derivado de patologia(s) ou anormalidade(s), estando no conceito ético ou psicológico de um indivíduo ou grupos isolados, ou ainda no campo da irracionalidade, que seria combatida através 
da punição estatal em ultima ratio pelo direito penal e por indenizações na seara cível. Ocorre por meio da manifestação da discriminação direta. Por estar ligado ao comportamento, o modo de combate será por meio da educação, conscientização e estímulo a mudanças sociais. O racismo é imoral, ou seja, um delito. Nas palavras de Silvio, trata-se de uma obsessão pela legalidade, já que "focar muito em lei é esquecer que várias atrocidades foram feitas em seu percalço, com apoio de grandes líderes políticos e religiosos".

Institucional (implícito): nesse recorte o racismo não seria fruto de atos individuais por si só, mas resultado do funcionamento das instituições (três poderes, de instituições financeiras, das grandes corporações, empresas etc.), conferindo, ainda que indiretamente, desvantagens e privilégios baseados na cor de cada pessoa. $O$ poder atua como elemento principal da relação racial. Portanto, racismo é dominação. Dessa forma detêm o poder os grupos que exercem o domínio sobre a política e a economia da sociedade. Todavia, a mantença desse poder depende intimamente da capacidade dominatória de impor seus interesses através da sua institucionalização, regras e padrões de condutas e modos de racionalidade, que tornam naturalizados tais comportamentos, a ponto de se tornar "normal" e até mesmo "natural" o domínio. O racismo ocorre com o estabelecimento de parâmetros discriminatórios baseados na raça, servindo para manter a hegemonia do grupo racial no poder.

Estrutural (forma consciente ou inconsciente): atuaria em continuação da segunda concepção, porém num sentido mais abrangente, concluindo-se na estrutura social existente, ou seja, depende de mecanismos estatais, ideológicos, jurídicos e econômicos. Só funciona com essas estruturas. Nas lições de Silvio (2019, p. 47) "a instituição tem sua atuação condicionada a uma estrutura social previamente existente - com todos os conflitos que Ihe são inerentes". Entende-se que a instituição é racista porque a sociedade é racista, afinal é formada por pessoas saídas da sociedade. $\mathrm{O}$ racismo é parte da ordem social que a instituição visa resguardar. Não é algo criado pela instituição; é algo reproduzido por ela.

Explicando em miúdos, as instituições que não atuam ativamente enxergando os problemas sociais e atuando contra eles, acabam por reproduzir as mesmas atitudes 
tidas como "naturais" para a sociedade. Isso acontecerá nas escolas, empresas e até mesmo nos governos que não dão voz aos problemas como racismo e sexismo e acabam por reproduzir as práticas da sociedade, transformando o racismo em um ato estrutural.

Com isso em vista, foi criado o mito da meritocracia, no intuito de manter o status quo da estrutura. Para tanto, são utilizados como exemplos raros casos de negras que ascenderam de status social e que conseguiram melhorar suas condições de vida. Logo, no imaginário popular todas as outras conseguem. Um pensamento que reverte a culpa a vítima.

Elenca Silvio de Almeida apud Theodor Adorno (2019), a desigualdade racial vivenciada na forma de desemprego, pobreza e privação material só é entendida como falta de mérito dos indivíduos porque a soma do racismo histórico e da meritocracia permite que isso aconteça.

Olhando para o passado, a escravidão em sua introdução no Brasil tinha bases científicas para justificá-la. As fontes eruditas do racismo brasileiro nasceram na Europa no sec. XVIII, e de acordo com o antropólogo Roberto Damatta (1987), no séc. XIX, o racismo aparece em sua forma finalizada como uma ferramenta do imperialismo e como uma justificativa "natural" para a supremacia dos Europeus sobre o restante do mundo. Sendo este o tipo de racismo a que elite intelectual brasileira recorreria.

Damatta (1987, p. 68) diz que:

considerando que nossa independência foi obra dos estratos dominantes (...) não tendo por isso mérito de ser uma alavanca para transformações sociais, ela foi básica na medida em que apresentou à elite nacional e local a necessidade de criar suas próprias ideologias e mecanismos de racionalização para diferenças internas no país.

Pois bem, se antes a elite podia culpar o Rei e a Coroa Portuguesa pelas injustiças ocorridas no país, depois da independência a ideologia que eles buscaram ocorreu na forma da fábula das três raças e no racismo à brasileira. Ou seja, não foi um projeto 
de amadores; foi um projeto de reacionários para manter o status quo, libertando o escravo na lei, mas deixando-o sem condições de se libertar socialmente.

\section{CONCLUSÃO}

O racismo poderia ser considerado como parte da história dos nossos antepassados ou resquícios de um período de colonização, entretanto, ele permanece vivo no imaginário social, em nossas instituições, se camuflando, aparecendo na forma do racismo recreativo e seus tons jocosos, em uma ordem social que é, em tese, democrática, que mantém vívida as relações de gênero-raça-classe, instituídas no período colonial.

As mulheres negras tiveram vivências histórica diferenciada que o feminismo em sua versão inicial clássica não reconhecia, assim como o Estado não tem dado conta da diferença qualitativa que o efeito interseccionalizado de opressões teve e ainda tem na identidade social das mulheres negras.

Atualmente o racismo sobrevive com nova roupagem. Por isso, os direitos existenciais básicos são necessários para o exercício da liberdade, da autodeterminação. E sem o mínimo existencial, as possibilidades de sobrevivência em nossa atual sociedade se mostram miseráveis, em alguns casos, até mesmo, impossíveis.

Não identificar as diferenças existentes entre as mulheres, trouxe impacto direto no modo e na frequência com que a lei é cumprida pelo público masculino, pela comunidade e efetivada pelo Estado. Apesar de algumas conquistas importantes, os direitos fundamentais, que são instrumentos para a concretização da dignidade da pessoa humana no Brasil, carecem de um cuidado especial e de efetivação das políticas públicas.

Percebe-se que as desigualdades não foram unificadas para combate; ora foram tratadas como problemas de gênero, ora como problemas raciais, mas não como um problema de gênero-raça e em muitos casos de classe também, como Almeida, Akotirene e Crunshaw bem colocam. 
Sem contar que, como visto a lei por si só não muda as atitudes sociais, principalmente quando não foi estudado esmiuçadamente o cenário para o qual ela, em tese, deveria incidir.

É importante perceber que as condições de subalternidade da mulher negra promovem o ambiente propício para a instalação da violência contra elas. A vulnerabilidade financeira, derivada de sua condição social, que é condicionada pela sua cor, é um ciclo social vicioso.

Isso se dá porque o racismo estrutural seria fruto de ações negligentes na esfera econômica, política e jurídica nacional. O racismo existente em nossa sociedade transcende a ação individual, pois as instituições reproduzem as condições sociais como meio de estabelecer e manter a ordem social. Desta maneira regula a ordem social que visa resguardar, o que torna a realidade quase imutável; uma vez que, além de termos uma sociedade racista, ainda temos as instituições preservando esse ideal.

É preciso atentar ao fato de que o racismo traz vários prejuízos às vítimas. Ele impede que estas adquiram a condição de pessoa e dela usufrua livremente. Há, portanto, uma objetificação do ser humano. Os danos são tamanhos que diversos são os estudos psicanalíticos sobre os danos psicológicos desenvolvidos pelas vítimas. Dentre eles podemos citar os respeitáveis trabalhos da portuguesa Grada Kilomba[13] (2019) e do francês Frantz Fanon[14] (2008). Motivo pelo qual não se fala em "racismo reverso" contra pessoas brancas, pois estas não sofrem prejuízos sociais em razão de sua cor de pele.

Assim, nesta celeuma, podemos concluir que a efetividade social da norma de direito fundamental à vida das mulheres negras não se concretiza de maneira significativa, conforme dados colhidos em pesquisas nacionais. Vislumbrando os dados acima mencionados, criou-se, paralelamente, ao ideal deduzido pela Carta Magna, uma resistência social masculina em respeitar a norma constitucional, assim como do próprio Estado em concretizar o ideal por ele prometido, fazendo com que um direito fundamental de primeira dimensão (direito à vida), que deveria ter, em tese, eficácia plena e aplicabilidade imediata, seja relegado aos efeitos de um direito de segunda 
dimensão. Assim, o direito à vida feminina negra foi transformado em um direito programático porque a sua eficácia social não foi alcançada.

Enfatiza-se, o olhar estatal estava voltado para um racismo no aspecto individualista, que se combatia com normas mais severas e educação, ao passo que o racismo presente em nossa sociedade é estrutural e se combate com mudanças efetivas dentro das instituições, com mais ações afirmativas e com a reformulação das mídias sociais.

Finalmente, em um mundo em que a necropolítica[15] define quem vive e quem morre, não tomar a etnia, dentre outros componentes da identidade social, como elementos de análise das grandes questões contemporâneas demonstra a falta de compromisso com a academia e com os problemas mundiais.

\section{REFERÊNCIAS}

A efetividade das normas constitucionais revisitadas. Revista de direito da Procuradoria Geral do Estado do Rio de Janeiro. n. 48, p. 60-98, 1995.

A eficácia dos direitos fundamentais: uma teoria geral dos direitos fundamentais na perspectiva constitucional. 11. ed. rev. atual. Porto Alegre: Livraria do Advogado Editora, 2012.

ALMEIDA, Sílvio Luiz de. Racismo Estrutural. São Paulo. Pólen, 2019.

ALEXANDRINO, Marcelo e PAULO, Vicente. Direito Constitucional Descomplicado. São Paulo. Editora Método, 2020.

AKOTIRENE, Carla. O que é interseccionalidade. Coordenação Djamila Ribeiro. Belo Horizonte: Letramento, 2018.

ATLAS DA VIOLÊNCIA 2019. Instituto de Pesquisa Econômica Aplicada (Org.); Fórum Brasileiro de Segurança Pública (Org.). Brasília. Rio de Janeiro. São 
Paulo. Instituto de Pesquisa Econômica Aplicada; Fórum Brasileiro de Segurança Pública.

BARROSO, Luís Roberto. Curso de direito constitucional contemporâneo: os conceitos fundamentais e a construção do novo modelo. 7. ed. São Paulo. Saraiva Educação, 2018.

BRANCO, Paulo Gustavo Gonet e MENDES, Gilmar Ferreira. Curso de Direito Constitucional. 12. ed. Saraiva Educação, 2017.

CARNEIRO, Sueli. Enegrecer o feminismo: a situação da mulher negra na América Latina a partir de uma perspectiva de gênero. In: ASHOKA Empreendimentos Sociais; TAKANO Cidadania (Orgs.). Racismos contemporâneos. Rio de janeiro; Takano Editora, 2003.

CRENSHAW, Kimberlé. A intersecionalidade na discriminação de raça e gênero. Disponível em: http://www.acaoeducativa.org.br/fdh/wpcontent/uploads/2012/09/Kimberle-Crenshaw.pdf. setembro de 2012. Acesso em: 13 de junho de 2020.

DAMATTA, Roberto. "Digressão: A fábula das três raças, ou o problema do racismo à brasileira". In: Roberto da DaMatta, Relativizando: uma introdução à antropologia social. Rio de Janeiro: Rocco, 1987, pags. 58- 85.

DATASENADO, Pesquisa. Violência Doméstica e Familiar contra a Mulher. Disponível

em: https://www.migalhas.com.br/arquivos/2020/3/557F54C5321F47_SENADORelat orio_Violencia_Dome.pdf Acesso em: 13 de junho de 2020.

Dicionário Brasileiro da Língua Portuguesa. Disponível em: https://michaelis.uol.com.br/moderno-portugues/busca/portugues-brasileiro/vida. Acesso: 16 de outubro de 2020. 
FANON, Frantz. Pele Negra, Máscaras Brancas; tradução de Renato da Silveira. Salvador: EDUFBA, 2008.

FERNANDES, Bernado Gonçalves. Curso de Direito Constitucional. 8. Ed Salvador: Juspodiv, 2016.

FRANCISCO, Mônica. A Dororidade e a Dor que só as Mulheres Negras Reconhecem. Portal Geledés, 2017. Disponível em: https://www.geledes.org.br/dororidade-e-dorque-so-as-mulheres-negrasreconhecem/?gclid=CjwKCAjwqML6BRAHEiwAdquMnYjGzFv8mdvLPLAhZxJ8oSn4 KuGODW3xphifK7pL7Kgd1JobqrvAuRoCYW4QAvD_BwE. Acesso em 03 de set. 2020.

GONZALES, Lélia.Racismo e Sexismo na Cultura Brasileira. Revista Ciências Sociais Hoje, $1984 . \quad$ Disponível em: https://edisciplinas.usp.br/pluginfile.php/4584956/mod_resource/content/1/06\%20\%20GONZALES\%2C\%20L\%C3\%A9lia\%20\%20Racismo_e_Sexismo_na_Cultura_Brasileira\%20\%281\%29.pdf. Acesso em: 03 de set. 2020.

IBGE: Pesquisa Nacional por Amostra de Domicílios: síntese de indicadores 2015. Coordenação de Trabalho e Rendimento. Rio de Janeiro, 2016.

IGNACIO, Julia. Necropolítica: 0 que esse termo significa. Disponível em: https://www.politize.com.br/necropolitica-o-que-e/. Acesso em: 16 de outubro de 2020.

KILOMBA, Grada. Memórias da Plantação: episódios de racismo cotidiano. Rio de Janeiro: Cobogó, 2019.

Pesquisa Nacional por Amostra de Domicílios (PNAD) 2020. Disponível em: Acesso em: 2020

JUSTIÇA, Conselho Nacional. Dados de Violência Doméstica e Feminicídio no Brasil (2016 a 2018). Disponível em: https://www.cnj.jus.br/wp- 
content/uploads/2019/03/c7bb60579ffe93584acf30929c349c50.pdf. Acesso em: 13 junho de 2020.

MENDES, Gilmar Ferreira Mendes, e BRANCO, Paulo Gustavo Gonet. Curso de direito constitucional - 6. Ed ver e atual: São Paulo, SaraivaJur, 2011.PIEDADE, Vilma. Dororidade. São Paulo: Editora Nós, 2017.

OLIVETO, Paloma. Subrepresentada, Bancada de Mulheres Negras Crescerá 30\% em 2019. Correio Brasiliense, 2018. Disponível em: https://www.correiobraziliense.com.br/app/noticia/politica/2018/10/20/interna_politica, 713916/subrepresentada-bancada-de-mulheres-negras-crescera-30-em-2019.shtml. Acesso em 05 de set. 2020.

REALE, Miguel. Lições Preliminares de Direito. 25 ed. 2001.

RODRIGUES, Léo. Em 91,7\% das Cidades do País, Não Há Delegacia de Atendimento

à Mulher.

Agência

Brasil,

2019.

Disponível

em: https://agenciabrasil.ebc.com.br/direitos-humanos/noticia/2019-09/em-917-dascidades-do-pais-nao-ha-delegacia-de-atendimento-mulher. Acesso em 27 de ago. 2020 .

SANTOS, Marcos André Couto. A efetividade das normas constitucionais (normas programáticas e a crise constitucional). Brasília: Revista de Informação Legislativa, 2000.

SARLET, Ingo Wolfgang. Dignidade da pessoa humana e direitos fundamentais na Constituição de 1988. 10. ed. rev. E at. Porto Alegre: Livraria do Advogado, 2019.

SILVA, José Afonso da. Curso de Direito Constitucional Positivo, 25 ed. São Paulo. Malheiros Editores, 2005.

VALESCO, Carla e TEIXEIRA, Milena. Mães Negras e Solteiras Sofrem Mais com A Falta de Saneamento e Carências nas Casas. G1, 2020. Disponível em: 
https://g1.globo.com/economia/noticia/2020/03/06/maes-negras-e-solteiras-sofremmais-com-falta-de-saneamento-e-carencias-nas-casas.ghtml. Acesso em 05 de set. 2020.

\section{APÊNDICE - REFERÊNCIAS DE NOTA DE RODAPÉ}

\section{Cantor, compositor e multi-instrumentista brasileiro.}

4. Pretuguês é a fusão, a mescla da língua do colonizador com a resistência linguística dos africanos, conforme explicava a autora do termo Lélia Gonzalez, "quando a gente fala em função materna, a gente tá dizendo que a mãe preta, ao exercê-la, passou todos os valores que Ihe diziam respeito pra criança brasileira, como diz Caio Prado Júnior. Essa criança, esse infans, é a dita cultura brasileira, cuja língua é o pretuguês". Disponível em: https://edisciplinas.usp.br/pluginfile.php/4584956/mod_resource/content/1/06\%20\%20GONZALES\%2C\%20L\%C3\%A9lia\%20\%20Racismo_e_Sexismo_na_Cultura_Brasileira\%20\%281\%29.pdf. Acesso: 03 de set. 2020.

5. Lélia Gonzalez foi professora, intelectual, ativista negra e fundadora do Movimento Negro Unificado (MNU).

6. Lugar de fala é a ideia (instrumento) que visa oferecer visibilidade a sujeitos marginalizados, abrindo espaço para que todas as vozes sejam ouvidas.

7. Dororidade, termo cunhado por Vilma Piedade, "é a cumplicidade entre mulheres negras, pois existe dor que só as mulheres negras reconhecem". Disponível em: https://www.geledes.org.br/dororidade-e-dor-que-so-as-mulheres-negrasreconhecem/?gclid=CjwKCAjwqML6BRAHEiwAdquMnYjGzFv8mdvLPLAhZxJ8oSn4 KuGODW3xphifK7pL7Kgd1JobqrvAuRoCYW4QAvD_BwE. Acesso em 03 de set. 2020 .

8. Barroso (2018) cita uma segunda vertente sobre somente os direitos individuais serem elegíveis de proteção: (...) diversos autores sustentam que o constituinte 
empregou a espécie pelo gênero, de modo que a proteção deve recair sobre todos os direitos fundamentais, e não apenas sobre os individuais. Até porque, segundo concepção corrente no direito internacional dos direitos humanos, as categorias ou gerações desses direitos são indivisíveis, isto é, não podem ser adequadamente protegidas de forma isolada umas das outras.

9. Definição dada pelo Dicionário Brasileiro da Língua Portuguesa.

10. https://agenciabrasil.ebc.com.br/direitos-humanos/noticia/2019-09/em-917-dascidades-do-pais-nao-ha-delegacia-de-atendimento-mulher. Acesso em 27 de ago. 2020 .

11.

https://www.correiobraziliense.com.br/app/noticia/politica/2018/10/20/interna_politica, 713916/subrepresentada-bancada-de-mulheres-negras-crescera-30-em-2019.shtml. Acesso em 05 de set. 2020.

12. https://g1.globo.com/economia/noticia/2020/03/06/maes-negras-e-solteirassofrem-mais-com-falta-de-saneamento-e-carencias-nas-casas.ghtml. Acesso em 05 de set. 2020.

13. KILOMBA, Grada. Memórias da Plantação: episódios de racismo cotidiano. Rio de Janeiro: Cobogó, 2019.

14. FANON, Frantz. Pele Negra, Máscaras Brancas; tradução de Renato da Silveira. Salvador: EDUFBA, 2008.

15. termo criado pelo intelectual camaronês Achille Mbembe, traduzido no poder do Estado "para ditar quem pode viver e quem pode morrer".

Enviado: Outubro, 2020.

Aprovado: Outubro, 2020. 